\title{
Differentiation therapy: sesamin as an effective agent in targeting cancer stem-like side population cells of human gallbladder carcinoma
}

\author{
Xiang Kong ${ }^{1,2+}$, Ming-zhe Ma ${ }^{3+}$, Yan Zhang ${ }^{4+}$, Ming-zhe Weng ${ }^{3}$, Wei Gong ${ }^{3}$, Li-qun Guo ${ }^{2}$, Jun-xiu Zhang ${ }^{2}$, \\ Guo-dong Wang ${ }^{5}$, Qing Su ${ }^{1^{*}}$, Zhi-wei Quan ${ }^{3^{*}}$ and Jie-ren Yang ${ }^{2^{*}}$
}

\begin{abstract}
Background: Recent studies have demonstrated that side population (SP) cells isolated from various cancer cell lines and primary tumors possess stem cell-like properties. Sesamin, a food-derived agent, possesses anti-cancer activities both in vitro and in vivo. The present study was designed to determine whether sesamin also have effects on cancer stem-like SP cells from gallbladder cancer (GBC).

Methods: In this study, we sorted SP cells by flow cytometry. SP cells were cultured and treated with sesamin. Tumor-sphere formation, colony formation, Matrigel invasion and tumorigenic potential were determined. Expression of nuclear NF-KB, IL-6, p-Stat3, Twist, E-cadherin and Vimentin was measured by Western blot, immunofluorescence staining or RT-PCR analysis. Nuclear NF-kB activity and IL-6 protein level were assessed with ELISA. Xenograft tumors were generated in nude mice.

Results: After treated with sesamin, SP cells differentiated into cells expressing the epithelial marker (E-cadherin). Sesamin effectively affected SP cells stem cell-like characteristics (i.e., tumor-sphere formation, colony-formation, Matrigel invasion), weakened the drug-resistance of SP cells and inhibited tumor growth both in vitro and in vivo. Treatment with sesamin significantly reduced the expression of nuclear NF-kB, IL-6, p-Stat3, Twist and Vimentin (a mesenchymal marker) in SP cells. Nuclear NF-KB activity and IL-6 level were also decreased after treatment with sesamin.
\end{abstract}

Conclusion: Food-derived sesamin directs the epithelial differentiation of cancer stem-like SP cells from GBC, which is associated with attenuation of NF-KB-IL-6-Stat3-Twist signal pathway.

\section{Background}

Gallbladder cancer (GBC) is the most common biliary tract cancer and the fifth most common gastrointestinal malignancy [1]. The outcome of patients with more advanced disease is dismal with 5-year survival rates ranging from $20 \%$ to $40 \%$ [2]. Despite advances in chemoradiation and adjuvant chemotherapy, chemotherapeutic

\footnotetext{
*Correspondence: suqingxinhua@163.com; zhiwquan@163.com; wnmcyaoli@sina.com

${ }^{\dagger}$ Equal contributors

${ }^{1}$ Department of Endocrinology, Xinhua Hospital, Shanghai Jiaotong University School of Medicine, Shanghai 200092, China

${ }^{3}$ Department of General Surgery, Xinhua Hospital, Shanghai Jiaotong

University School of Medicine, Shanghai 200092, China

${ }^{2}$ Department of Pharmacology, Wannan Medical College, Wuhu, Anhui

241002, China

Full list of author information is available at the end of the article
}

options prolong life minimally as chemo-resistance is one of the most remarkable characteristics of GBC [3].

The concepts of cancer stem cells (CSCs) or tumorinitiating cells have proposed that the heterogeneous tumor cell population contains a small population of cells with properties such as self-renewal, multiplex differentiation, chemo- and radio-resistance, high tumorigenicity, and they may play pivotal parts in the development, progression, metastasis, recurrence and multidrug resistance of cancer [4,5]. In this study, we employed the sidepopulation (SP) cells, which are enriched in a subset of cancer stem-like cells and are considered as CSCs in a variety of cancer [6-9].

Sesamin is isolated from the oil of sesame seeds and exerts a variety of biological activities, including lipidlowering, antihypertensive and antitumor effects [10-12]. 
Regarding its antitumor effects, sesamin has been demonstrated to inhibit the growth of a variety of cancer cells both in vivo and in vitro, including breast cancer $[13,14]$, human lung cancer [15] and colon cancer [16]. The mechanisms by which sesamin exerts antitumor effects are not fully understood, but its role in suppression of NF-kB and interleukin 6 (IL-6) have been clarified $[12,17]$. In fact, NF- $\mathrm{kB}$ and IL-6 is vital in the epigenetic switch from immortalized breast cells to a stably transformed line that contains CSCs [18]. IL-6 promoted E-cadherin repression, which has been implicated in the generation of a stem cell phenotype $[19,20]$. And besides, accumulating evidences have linked epithelialmesenchymal transition (EMT) to CSCs. Down-regulation of E-cadherin generates a mesenchymal phenotype, which displays stem cell-like characteristics [21]. We therefore investigated whether sesamin could modify the stem cell-like characteristics of SP cells through inducing the epithelial differentiation. We further explored the underlying mechanisms of the effects that sesamin exerts on SP cells of GBC.

\section{Methods}

\section{Ethics statement}

All animal experiments were performed in animal laboratory center of Xinhua Hospital and in accordance with the Guide for the Care and Use of Laboratory Animals published by the US National Institutes of Health (NIH publication no. 85-23, revised 1996). The study protocol was approved by the Animal Care and Use committee of Xinhua Hospital.

\section{Cell culture}

Two human GBC cell lines were used in the experiment. SGC-996 and GBC-SD were purchased from Cell Bank of the Chinese Academy of Science (Shanghai, China). SGC-996 and GBC-SD cell lines were cultured in Dulbecco's modified Eagle's medium (DMEM, Gibco BRL), containg $10 \%$ fetal bovine serum (FBS, HyClone) as well as $100 \mathrm{U} / \mathrm{ml}$ penicillin and $100 \mu \mathrm{g} / \mathrm{ml}$ streptomycin. Cells were maintained at $37^{\circ} \mathrm{C}$ in $5 \% \mathrm{CO}_{2}$. Sesamin (>94\% purity) was provided by Tianyi Lvbao Technology Co. (Wuhu, China) [11]. Sesamin was dissolved in DMSO as $0,11,33.3,100 \mu \mathrm{M}$ stock solution. Vehicle control consisted of DMSO equivalent to treatments.

\section{Flow cytometry analyses}

To sort the SP cells from GBC cell lines, cells were trypsinized in a logarithmic growth phase and washed with DMEM containing $2 \% \mathrm{FBS}$ and $10 \mathrm{mmol} / \mathrm{L}$ of HEPES twice. For each SP analysis, cells $\left(1 \times 10^{6}\right.$ cells $\left./ \mathrm{mL}\right)$ were incubated in pre-warmed DMEM with $2 \%$ FBS containing freshly added Hoechst $33342(5 \mu \mathrm{g} / \mathrm{mL}$ final concentration) in the presence or absence of $50 \mu \mathrm{g} / \mathrm{ml}$ verapamil
(Sigma-Aldrich) for 90 minutes at $37^{\circ} \mathrm{C}$ in water bath. During the incubation time, cells were protected from light and mixed by gentle vortexing every 15 minutes. At the end of the incubation, samples were washed with Hank's Balanced Salt Solution supplemented with 2\% FBS and $10 \mathrm{mmol} / \mathrm{L}$ of HEPES and re-suspended at a final concentration of $1 \times 10^{6}$ cells $/ \mathrm{mL}$. Before running samples on a flow cytometer (Becton Dickinson), propidium iodide was added to a final concentration of $1 \mu \mathrm{g} / \mathrm{mL}$ to exclude dead cells. Hoechst 33342 was excited with an ultraviolet laser at $350 \mathrm{~nm}$, and fluorescence emission was measured with DF 424/44 (Hoechst blue) and DF 630/22 (Hoechst red) optical filters.

To determine the multi-differentiation capacity of SP cells, cells were cultured under differentiating conditions (DMEM supplemented with 10\% FBS in the absence of growth factors). Cells were retained with Hoechst dye at 3 and 7 days, and the fraction of SP cells was analyzed with flow cytometer.

To determine the effects of sesamin on SP cells population, the sorted SP cells were given various concentrations of sesa$\min (0,11,33.3,100 \mu \mathrm{M})$ for 7 days in un-differentiating conditions: DMEM/F12 medium (Gibco BRL) supplemented with $20 \mathrm{ng} / \mathrm{mL}$ human recombinant epidermal growth factor (EGF; Invitrogen) and $10 \mathrm{ng} / \mathrm{mL}$ human recombinant basic fibroblast growth factor (bFGF; Invitrogen), as well as $100 \mathrm{U} / \mathrm{ml}$ penicillin and $100 \mu \mathrm{g} / \mathrm{ml}$ streptomycin. The fraction of SP cells was analyzed by flow cytometry. Cells without sesamin treatment were set as control group.

\section{In vitro propagation of SP cells and tumor-sphere assay} For in vitro propagation, the sorted SP cells were plated on ultralow attachment six well plates (Sigma-Aldrich) at a density of $2 \times 10^{4}$ cells $/ \mathrm{mL}$ in un-differentiating conditions: DMEM/F12 medium supplemented with $20 \mathrm{ng} / \mathrm{mL}$ EGF and $10 \mathrm{ng} / \mathrm{mL}$ bFGF. Additional $0.5 \mathrm{~mL}$ of medium was added every two days. Cell aggregates known as tumor-spheres were formed within 3 days after seeding.

To test the tumor-sphere formation ability, SP cells and non-SP cells were seeded at $5 \times 10^{3}$ cells $/ \mathrm{mL}$ in DMEM/F12 medium supplemented with $20 \mathrm{ng} / \mathrm{mL}$ EGF and $10 \mathrm{ng} / \mathrm{mL}$ bFGF. After 7 days, the formed tumorspheres derived from SP cells were collected, trypsinized into single-cell suspensions and re-cultured in DMEM/ F12 medium supplemented with $20 \mathrm{ng} / \mathrm{mL}$ EGF and $10 \mathrm{ng} / \mathrm{mL}$ bFGF to form secondary tumor-spheres. After exposing to sesamin at various concentrations $(0,11$, 33.3, $100 \mu \mathrm{M})$ in DMEM/F12 medium supplemented with $20 \mathrm{ng} / \mathrm{mL}$ EGF and $10 \mathrm{ng} / \mathrm{mL}$ bFGF for 7 days, the number of tumor-spheres formed were observed and counted utilizing a Leica DC 200 microscope. The control group was without treatment with sesamin. 


\section{Colony formation assay}

To examine clonogenic ability, non-SP cells, SP cells and SP cells pretreated with sesamin of various concentrations $(0,11,33,100 \mu \mathrm{M})$ for 7 days were seeded in six-well plates at a density of 200 cells/well and maintained in DMEM with $10 \%$ FBS. Cells were washed with phosphate buffered saline (PBS), fixed in methanol for 15 minutes and stained with $0.5 \%$ crystal violet for 15 minutes. The plates were then photographed, and the colonies were counted.

\section{Matrigel invasion assay}

Inserts with $8 \mu \mathrm{M}$ pore (Millipore) were pre-coated with matrigel (BD Biosciences) at a concentration of $3 \mathrm{mg} / \mathrm{mL}$ for 3 hours. Non-SP cells, SP cells and SP cells pretreated with sesamin of various concentrations $(0,11,33$, $100 \mu \mathrm{M})$ for 7 days at a density of $1 \times 10^{4}$ viable cells in $200 \mu \mathrm{l}$ of serum-free DMEM medium of each permutation were added to their respective upper chamber, DMEM + $10 \%$ FBS was placed in the lower compartments as chemo-attractants. The plates were incubated for 24 hours at $37^{\circ} \mathrm{C}$ in $5 \% \mathrm{CO}_{2}$ atmosphere. At the end of incubation, cells that did not migrate or invade through the pores were removed by a cotton swab. Cells on the lower surface were fixed in ice-cold 100\% methanol, stained in $0.5 \%$ crystal violet and scored as the mean number of invaded cells per 5 random optical fields at $20 \times$ magnification.

\section{Immunofluorescence microscopy}

For membrane staining (E-cadherin), cells were fixed by incubation with cold $100 \%$ methanol for 10 minutes. For intracellular staining (Vimentin), the cells were fixed with $4 \%$ (wt/vol) paraformaldehyde in PBS and permeabilized by incubation with $0.5 \%$ Triton X-100 in PBS for 1 minute. The cells were incubated with $3 \%$ bovine serum albumin in PBS for 30 minutes at room temperature. After washing with PBS, the cells were incubated with specific primary antibody at $4{ }^{\circ} \mathrm{C}$ overnight. The cells were then washed and incubated with Alexa Fluor 488- or 555-conjugated goat anti-rabbit IgG diluted in blocking solutions and incubated for 1 hour. The nuclei were stained with 4,6-diamidino2-phenylindole (DAPI). Sections were visualized by fluorescence microscopy. SP cells were cultured under differentiating conditions (DMEM supplemented with $10 \%$ FBS in the absence of growth factors) for 7 days to allow cells attachment and differentiation. In addition, SP cells were treated with $100 \mu \mathrm{M}$ sesamin for 7 days in DMEM/F12 medium supplemented with $20 \mathrm{ng} / \mathrm{mL}$ EGF and $10 \mathrm{ng} / \mathrm{mL}$ bFGF. The acquisition of epithelial markers (E-cadherin) and loss of mesenchymal markers (Vimentin) were evaluated by immunofluorescence as indicated above.

\section{Cell proliferation assay}

Cell proliferation assays were conducted using the CCK-8 assay kits as described by the manufacturer. Sorted SP cells and non-SP cells were cultured in 96-well plates for 3 days in DMEM/F12 medium supplemented with $20 \mathrm{ng} / \mathrm{mL}$ EGF and $10 \mathrm{ng} / \mathrm{mL} \mathrm{bFGF}$. For the chemoresistance of SP cells, the same amount of SP and non$\mathrm{SP}$ cells were treated with cisplatin at a range of concentrations $(0,2,4,8,16 \mu \mathrm{M})$ for 96 hours in DMEM/F12 medium supplemented with $20 \mathrm{ng} / \mathrm{mL}$ EGF and $10 \mathrm{ng} / \mathrm{mL}$ bFGF. Treatment with sesamin at a variety of concentrations $(0,11,33.3,100 \mu \mathrm{M})$ for 3 and 7 days in DMEM/F12 medium supplemented with $20 \mathrm{ng} / \mathrm{mL}$ EGF and $10 \mathrm{ng} / \mathrm{mL}$ bFGF was performed to test the tumor-inhibition effects on SP cells. For the chemosensitization effects of sesamin on SP cells, sesamin alone $(33.3 \mu \mathrm{M})$, cisplatin alone $(4 \mu \mathrm{M})$, sesamin plus cisplatin (33.3 plus $4 \mu \mathrm{M})$ were added to respective wells for an incubation of 7 days.

\section{IL-6 ELISA assay}

Sorted SP cells and non-SP cells were cultured in 96-well plates at a density of $2 \times 10^{4}$ cells/mL in DMEM/F12 medium supplemented with $20 \mathrm{ng} / \mathrm{mL}$ EGF and $10 \mathrm{ng} / \mathrm{mL}$ bFGF. Conditioned medium was collected over 48 hours and the IL- 6 concentrations were tested utilizing the human IL-6 ELISA Development Kit (Peprotech) according to the manufacturer's instructions. Briefly, culture medium and IL-6 standards were incubated for 2 hours at room temperature in 96-well microplates, which were coated with IL-6 mAb. After washing, an antibody against IL-6 conjugated to alkaline phosphatase was added. Substrate and amplifier were added and the plates were read at $485 \mathrm{~nm}$. Similar procedures were performed to study the effects of sesamin $(0,11,33.3,100 \mu \mathrm{M})$ for 7 days on IL-6 production.

\section{Real-time reverse transcriptase PCR analysis}

For non-SP cells, SP cells and SP cells exposed to sesa$\min (0,11,33.3,100 \mu \mathrm{M})$ for 7 days, total cellular RNA were collected from cells using $1 \mathrm{~mL}$ of TRIzol reagent (Invitrogen), then the samples were reverse-transcribed using random hexamers and reverse transcriptase (Invitrogen) to obtain cDNA. The expression levels of IL-6 mRNAs were determined by real-time reverse transcriptase-PCR. All reactions were carried out on 96-well PCR plates (ABI PRISM, Applied Biosystems) in an ABI PRISM 7000 sequence detection system. Standard thermal cycling conditions are a hot start at $50^{\circ} \mathrm{C}$ for $5 \mathrm{~min}, 95^{\circ} \mathrm{C}$ $10 \mathrm{~min}$, followed by up to 50 cycles of: $95^{\circ} \mathrm{C} 15 \mathrm{sec}, 60^{\circ} \mathrm{C}$ for $1 \mathrm{~min}$. Data shown are normalized to GADPH expression. Primer sequences were as follows:

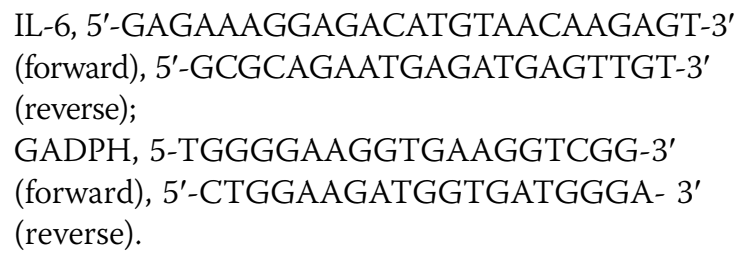




\section{Western blot analysis}

For non-SP cells, SP cells and SP cells exposed to sesamin $(0,11,33.3,100 \mu \mathrm{M})$ for 7 days, nuclear and cytosolic proteins were prepared using NE-PER Nuclear and Cytoplasmic Fractions Kit purchased from Thermo Scientific. Protein content was determined by Bradford assay. Equal amounts $(30-50 \mu \mathrm{g})$ of proteins were applied to an 8-12\% SDSpolyacrylamide separating gel and transferred to a PVDF membrane (Millipore). The membrane was blocked with $5 \%$ skim milk or $1 \%$ BSA in TBST and then probed with indicated primary antibodies with gentle shaking at $4{ }^{\circ} \mathrm{C}$ overnight. Primary antibodies against NF- $\mathrm{kB}$ (p65, 1:1000), E-cadherin (1:400), Vimentin (1:500), Twist (1:400) (Abcam), signal transducer and activator of transcription 3 (Stat3, 1:1000) and p-Stat3 (Tyr-705, 1:800) (Cell Signaling Technology) were used in this study. After washing the membranes three times, the immunoblots were incubated with the appropriated secondary antibodies for 1 hour. Antibody-bound proteins were detected by Millipore enhanced chemiluminescence kit.

\section{NF-KB/p65 activity assay}

The sorted SP cells were plated on ultralow attachment six well plates at a density of $2 \times 10^{4}$ cells $/ \mathrm{mL}$ in un- differentiating conditions: DMEM/F12 medium supplemented with $20 \mathrm{ng} / \mathrm{mL}$ EGF and $10 \mathrm{ng} / \mathrm{mL}$ bFGF. The sorted SP cells were treatment with sesamin at a variety of concentrations $(0,11,33.3,100 \mu \mathrm{M})$ for 7 days. Resuspend cell pellet in $0.5 \mathrm{ml}$ of ice cold Hypotonic Buffer (20 mM Tris-HCl, $10 \mathrm{mM} \mathrm{NaCl}, 1 \mathrm{mM}$ EDTA, $2 \mathrm{mM} \mathrm{Na} 3 \mathrm{VO} 4$, containing protease inhibitors) by pipetting up and down several times and transfer to a pre-chilled microcentrifuge tube. The cells were then lysed with $15 \mu \mathrm{l}$ of $10 \%$ nonyl phenoxylpolyethoxylethanol (NP-40). The nuclear pellet was resuspended in $30 \mu \mathrm{l}$ of Nuclear Lysis Buffer (Imgenex). Vortex vigorously and incubate suspension for $30 \mathrm{~min}$ on a rocking platform. Then, the extract was centrifuged, and the supernatant containing the nuclear extract was obtained.

NF- $\mathrm{kB}$ activity was measured by a NF-kB p65 ACTIVELISA kit (Imgenex) according the manufacturer's instruction. Briefly, Free p65 was captured by the anti-p65 antibody coated plate, then after adding a second anti-p65 antibody followed by alkaline phosphatase-conjugated secondary antibody the amount of bound p65 is detected using colorimetric detection in an ELISA plate reader at absorbance $405 \mathrm{~nm}$.

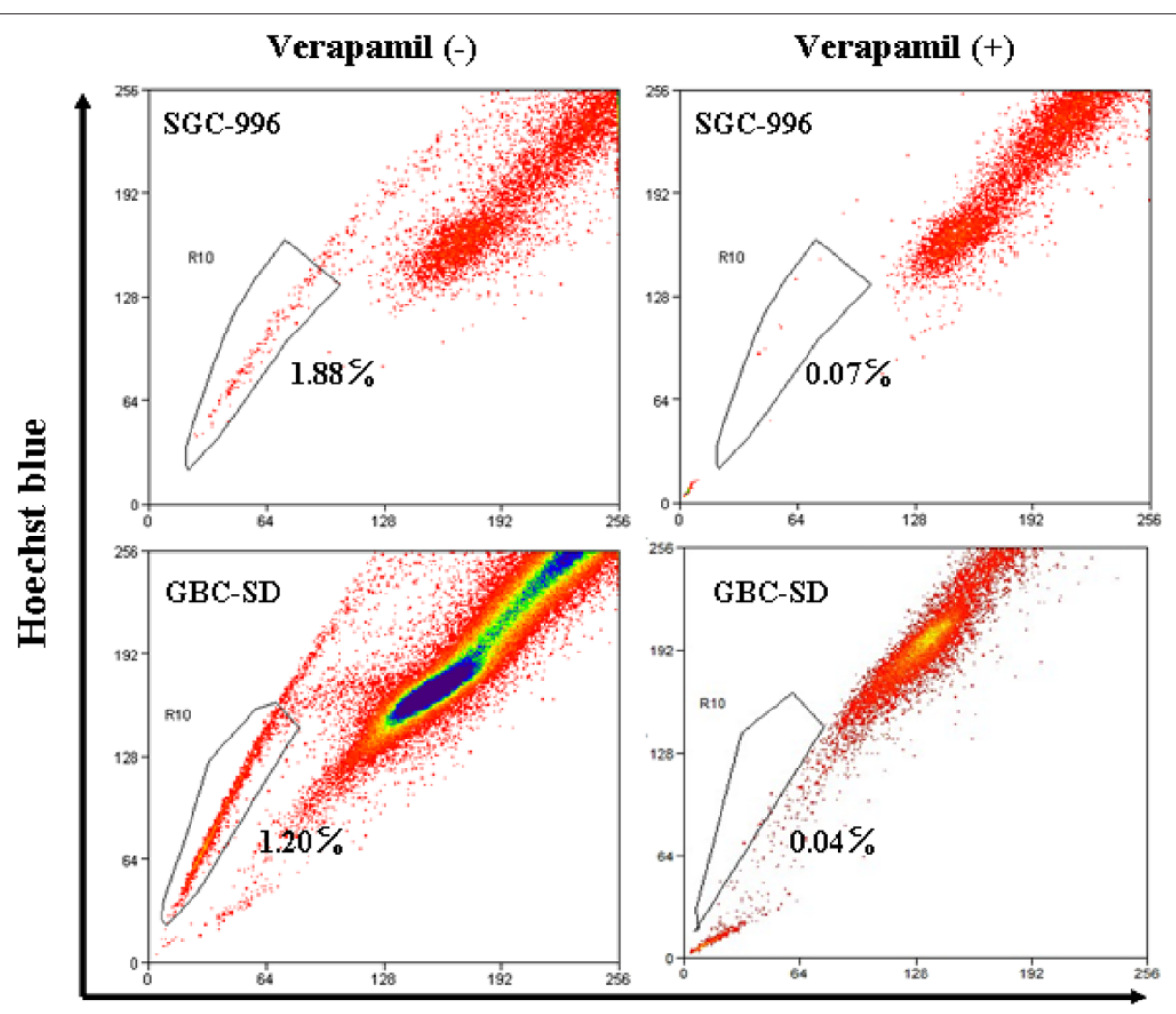

Hoechst red

Figure 1 SP cells analysis. The proportion of SP cells in SGC-996 and GBC-SD was analyzed by flow cytomertry. As a control, verapamil (50 $\mu M$ ) was added to inhibit the dye efflux activity. 


\section{In vivo tumor growth assay}

$1 \times 10^{2}$ to $1 \times 10^{6}$ cells/100 $\mu \mathrm{L}$ PBS of non-SP and SP cells were injected subcutaneously into 6-week-old nude mice ( $n=4$ per group). Caliper measurement of tumor volume (length $\times$ width) was conducted every week. Tumor volumes were calculated with the formula: length $(\mathrm{mm}) \times$ width $(\mathrm{mm})^{2} / 2$. In addition, after pretreated with sesamin $(100 \mu \mathrm{M})$ for 7 days, $1 \times 10^{5} \mathrm{SP}$ cells were injected subcutaneously into 6 -week-old nude mice ( $n=6$ each group). Tumor volumes were measured weekly.

\section{Statistical analysis}

Each experiment was carried out in duplicate and at least three independent experiments were done. Data were shown as mean $\pm \mathrm{SD}$. Comparisons among groups were determined by the use of ANOVA followed by a Newman-Keuls test. The difference was considered statistically significant when $p<0.05$.

\section{Results}

\section{Sorting the SP cells of GBC}

The proportion of SP cells were $1.85 \pm 0.31 \%$ and $1.14 \pm$ $0.23 \%$ obtained from SGC-996 and GBC-SD cell lines respectively, which decreased significantly in the presence of verapamil (Figure 1). Our sorting of SP cells was based on the ability to efflux the dye Hoechst 33342. Verapamil was used as a control to effectively block the efflux of the Hoechst dye, which reveals that this method of sorting SP cells is effective.

\section{Biological characteristics of cancer stem-like SP cells}

Self-renewal, multi-differentiation capacity, tumor initiation are proposed to be characteristics of CSCs [4]. Therefore, we determined the stem cell-like capacity of the SP cells both in vitro and in vivo. The cell viabilities of SP cells obtained from SGC-996 and GBC-SD were increased by $44 \%$ and $49 \%$ respectively compared to those in non-SP cells at day 3. In terms of self-renewal, SP cells had 13- and 20-fold higher tumor-sphere formation ability than the non-SP cells under un-differentiating conditions (Figure 2A). SP cells also demonstrated much higher colony formation ability compared with non-SP cells (Figure 2B). Furthermore, SP cells had elevated invasion capacity (Figure 2C). As shown in Figure 2D and E, SP cells were more chemo-resistant to the conventional drug cisplatin compared with non-SP cells.

To determine the multi-differentiation capacity of SP cells, sorted SP and non-SP cells were cultured in

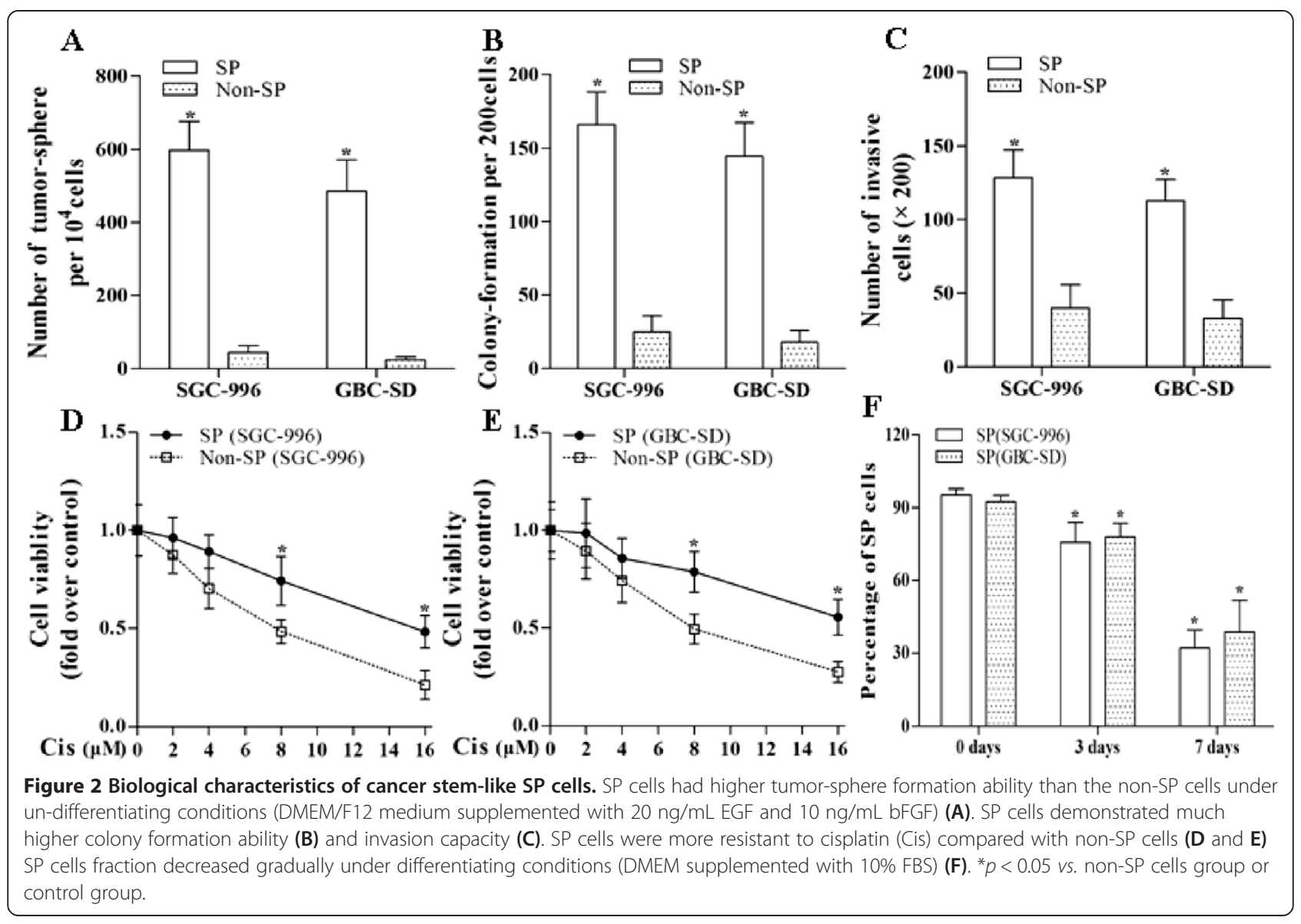


Table 1 Tumor incidence of SP cells and non-SP cells in vivo

\begin{tabular}{llllll}
\hline Cell population & $\mathbf{1 0}^{\mathbf{6}}$ & $\mathbf{1 0 ^ { \mathbf { 5 } }}$ & $\mathbf{1 0}^{\mathbf{4}}$ & $\mathbf{1 0}^{\mathbf{3}}$ & $\mathbf{1 0}^{\mathbf{2}}$ \\
& Tumors & Tumors & Tumors & Tumors & Tumors \\
\hline SP(SGC-996) & $4 / 4$ & $4 / 4$ & $3 / 4$ & $2 / 4$ & $2 / 4$ \\
Non-SP(SGC-996) & $4 / 4$ & $2 / 4$ & $1 / 4$ & $0 / 4$ & $0 / 4$ \\
SP(GBC-SD) & $4 / 4$ & $4 / 4$ & $4 / 4$ & $2 / 4$ & $2 / 4$ \\
Non-SP(GBC-SD) & $4 / 4$ & $3 / 4$ & $2 / 4$ & $0 / 4$ & $0 / 4$ \\
\hline
\end{tabular}

Increased tumorigenicity of SP cells when injected subcutaneously into nude mice ( $n=4$ per group). The observational period lasted for six weeks.

collagen-coated dishes under differentiating conditions. Our data indicated that the SP faction rapidly underwent a symmetric division and generated both SP and non-SP cells, namely the SP enriched population went down by approximately 66\%, 58\% from SGC-996 and GBC-SD cell lines respectively (Figure 2F). In sharp contrast, the sorted non-SP cells were not able to generated SP cells in this period of time (data not shown).

In the in vivo xenograft experiments, we found that the injection of SP cells, as few as $10^{2}$ cells per mouse, was able to generate tumor xenografts, while $10^{4}$ nonSP cells were much less tumorigenic (Table 1). In all, the SP cells of GBC were in accordance with the characteristics of CSCs. Therefore, we considered the SP cells as CSCs.

\section{Molecular characteristics of SP Cells}

The protein expression of p-Stat3, nuclear NF-кB, Vimentin and Twist detected by Western blot analysis was elevated in SP cells from SGC-996 and GBC-SD compared to non-SP cells. However, the expression of E-cadherin was just the opposite (Figure 3A). The mRNA and protein levels of IL-6 were also enhanced in SP cells compared to non-SP cells (Figure 3B and C). Immunofluorescence staining showed that SP cells harbored enhanced expressin of Vimentin and decreased expression of E-cadherin compared to parental cells (Figure 4). We also demonstrated that the expression level of Vimentin was decreased while E-cadherin was increased in SP cells under differentiating conditions (DMEM supplemented with 10\% FBS in the absence of growth factors) (Figure 4).

\section{Sesamin effectively reduced the SP cells population}

We measured the SP cells fraction after exposing to sesamin for 7 days under a non-differentiation condition. The results showed that sesamin significantly reduced the SP cells fraction in a dose-dependent manner, $100 \mu \mathrm{M}$ sesamin diminished the SP cells fraction from $86 \%$, 82\% to $41 \%, 48 \%$ for SGC-996 and GBC-SD at day 7, respectively (Figure 5A).

\section{Sesamin modified stem cell-like features of SP cells}

As shown in Figure 5B, sesamin markedly decreased the tumor-sphere formation ability of SP cells. Sesamin

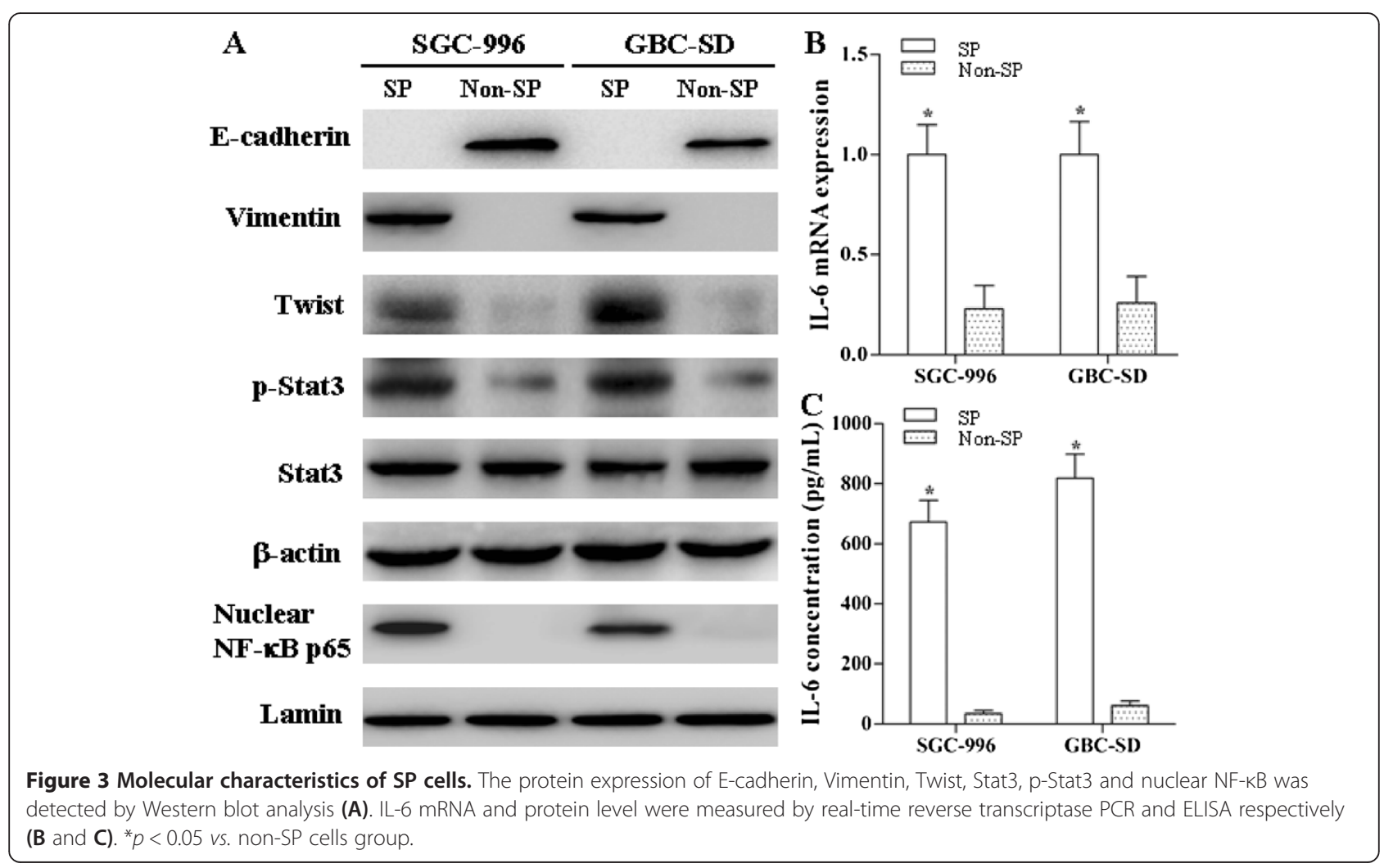




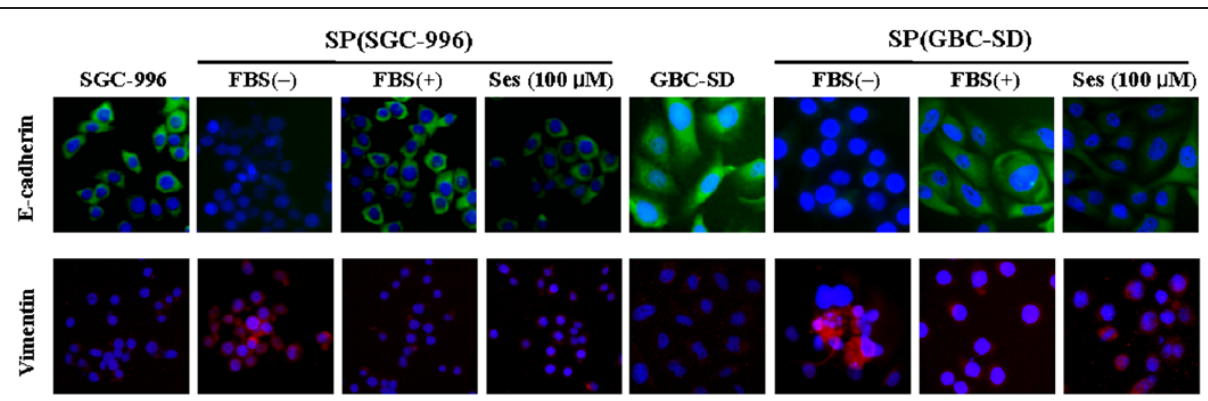

Figure 4 Immunofluorescence staining for E-cadherin and Vimentin. The expression of Vimentin and E-cadherin in SGC-996 and GBC-SD cells, SP cells in the absence or presence of the FBS, and SP cells treatment with $100 \mu \mathrm{M}$ sesamin for 7 days.

$(100 \mu \mathrm{M})$ reduced the number of tumor-spheres by as much as 59\%, 51\% for SGC-996 and GBC-SD respectively. Sesamin also obviously attenuated the colony formation and invasion capacities of SP cells (Figure 5C and D).

\section{Sesamin inhibited SP cells growth}

After treatment for 3 and 7 days, cell viability was assayed utilizing the CCK- 8 method. Our data revealed that sesamin effectively inhibited the viabilities of SP cells in a dose- and time-dependent manner. SP cells viabilities were obviously decreased by treatment with sesamin $(100 \mu \mathrm{M})$ to the extent of $41 \%, 48 \%$ for SGC-996 and GBC-SD at day 7 , respectively (Figure 6A and B).

\section{Sesamin sensitized SP cells to the chemotherapeutic agent cisplatin}

To explore the chemo-sensitization effect of sesamin, SP cells were treated with sesamin alone $(33.3 \mu \mathrm{M})$, cisplatin alone $(4 \mu \mathrm{M})$, sesamin plus cisplatin (33.3 plus $4 \mu \mathrm{M})$ for 7 days. Sesamin enhanced the chemotherapeutic effect of cisplatin on SP cells from both SGC-996 and GBC-SD (Figure 6C).

\section{Molecular mechanisms of sesamin targeting SP cells}

As shown in Figures 4, 7 and 8, sesamin enhanced the protein expression of E-cadherin (an epithelial marker), and decreased Vimentin (a mesenchymal marker) and Twist protein expression. We further examined the effects of sesamin on the NF-kB-IL-6-Stat3 pathway. Treatment with sesamin significantly decreased the protein expression of nuclear $\mathrm{p}$-Stat 3 and NF- $\mathrm{kB}$ as well as nuclear NF- $\mathrm{kB}$ activity (Figure 7A and E; Figure 8A and E; Figure 9). As shown in Figure 10, the mRNA expression and protein level of IL- 6 were markedly reduced after treatment with sesamin for 7 days.
A
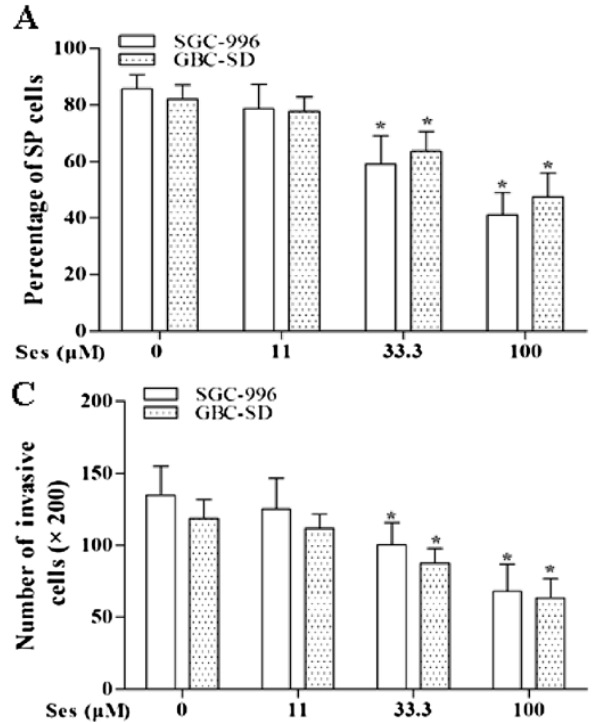

B
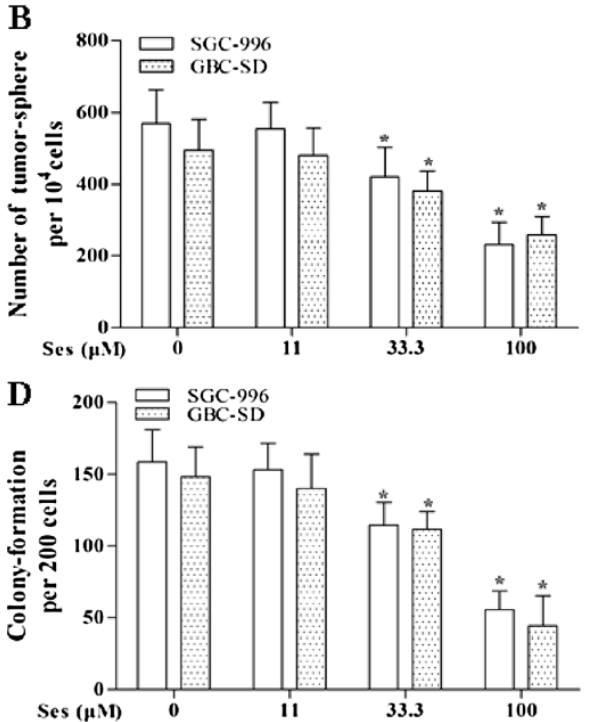

Figure 5 Sesamin exerted its effects on SP cells. Sesamin significantly decreased SP cells fraction in a dose-dependent manner (A). Sesamin reduced the tumor-sphere formation ability of SP cells (B). Sesamin reduced the invasion capacity of CSCs (C). Sesamin inhibited colony formation of SP cells from SGC-996 and GBC-SD (D). * $p<0.05$ vs. control group. Ses: sesamin. 


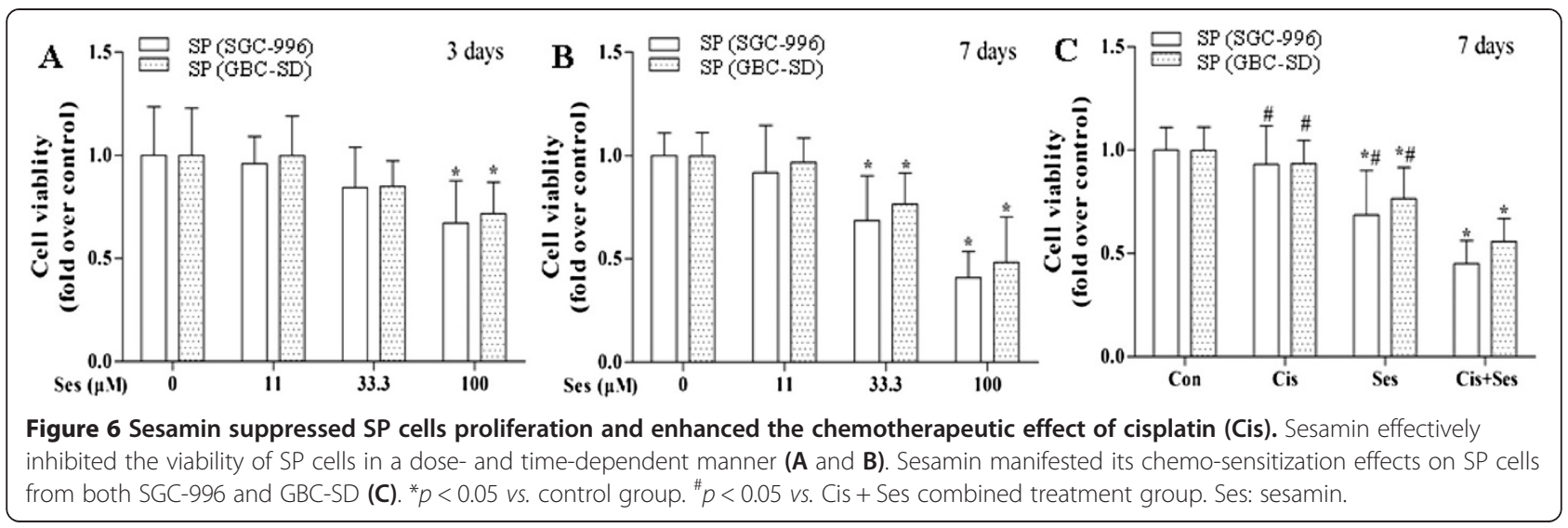

Sesamin reduced SP cells-derived tumor growth in vivo

We assessed the tumor-inhibition effects by pretreated SP cells with sesamin $(100 \mu \mathrm{M})$ alone for 7 days before injection. Difference in tumor volumes between the sesamin pretreatment group and the control group became significant since 28 days post inocubation. The results illustrated that sesamin significantly inhibited SP cells-derived tumor growth in vivo (Figure 11).

\section{Discussion}

There is growing evidence that many human cancers are actually driven and maintained by a population of cells with stem-like properties. In addition to mediating tumor invasion, metastasis and recurrence, the comparative resistance of CSCs to conventional chemotherapeutic agents and radiation therapies may contribute to treatment resistance [22]. Thus, it is important to develop new therapies targeting CSCs. The CSCs have been identified and isolated on the basis of their expression of specific combinations of molecules, e.g., CD133, CD44, ATP-binding cassette proteins and aldehyde dehydrogenase [23]. In this study, we enriched the SP cells via the Hoechst dye assay. Our results showed that SP cells of GBC exhibited the stem cell-like abilities such as self-renewal, multi-differentiation, tumor initiation and chemo-resistance.

EMT is a well-coordinated developmental programme that has a very important role in the development of the mesoderm from the epithelium during embryogenesis [24,25]. Induction of EMT via down-regulating E-cadherin generates a stem cell phenotype, which contributes to higher invasive and metastatic abilities [21,26]. Consistent with aforementioned reports, our results revealed that the mesenchymal marker Vimentin was expressed at higher

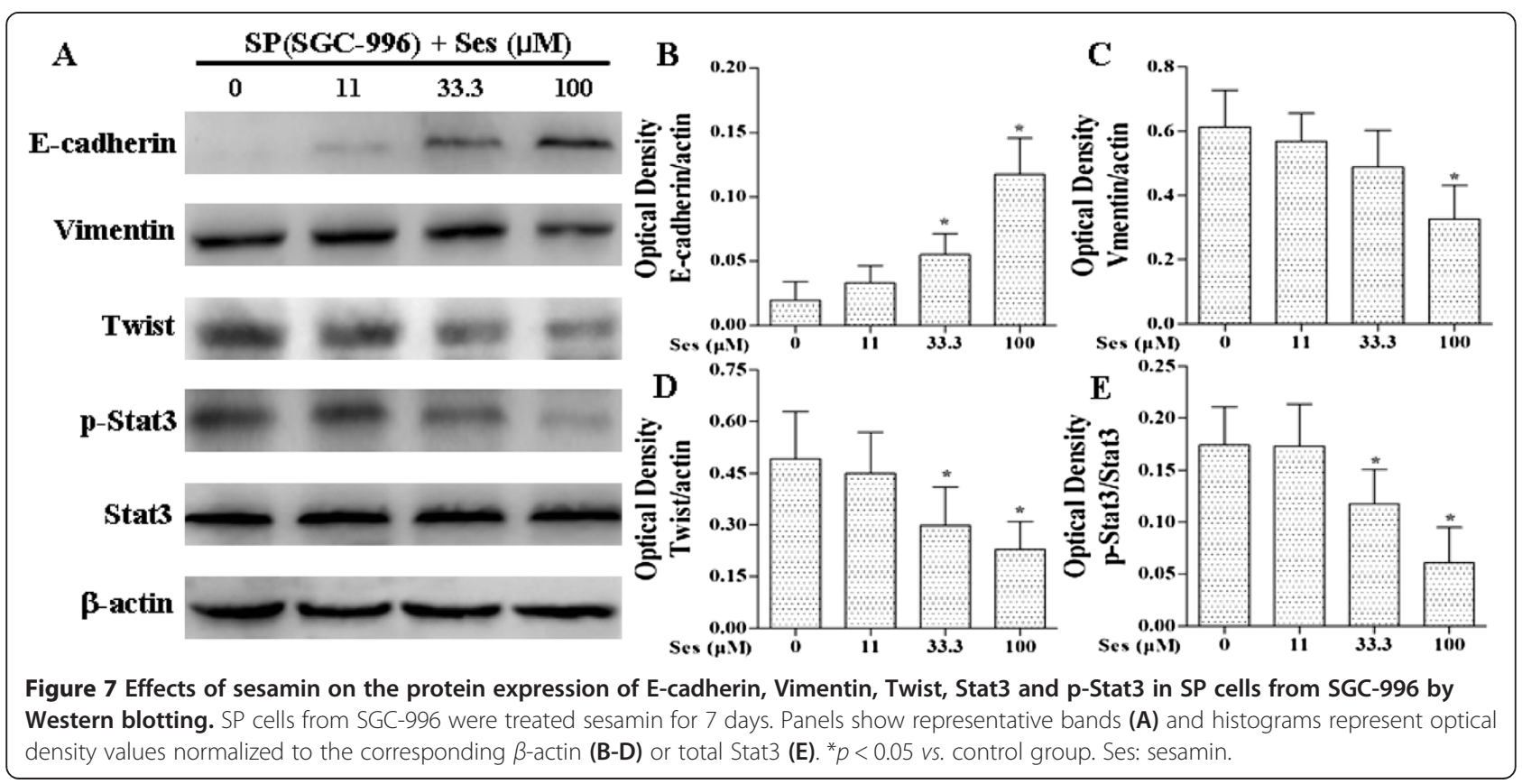



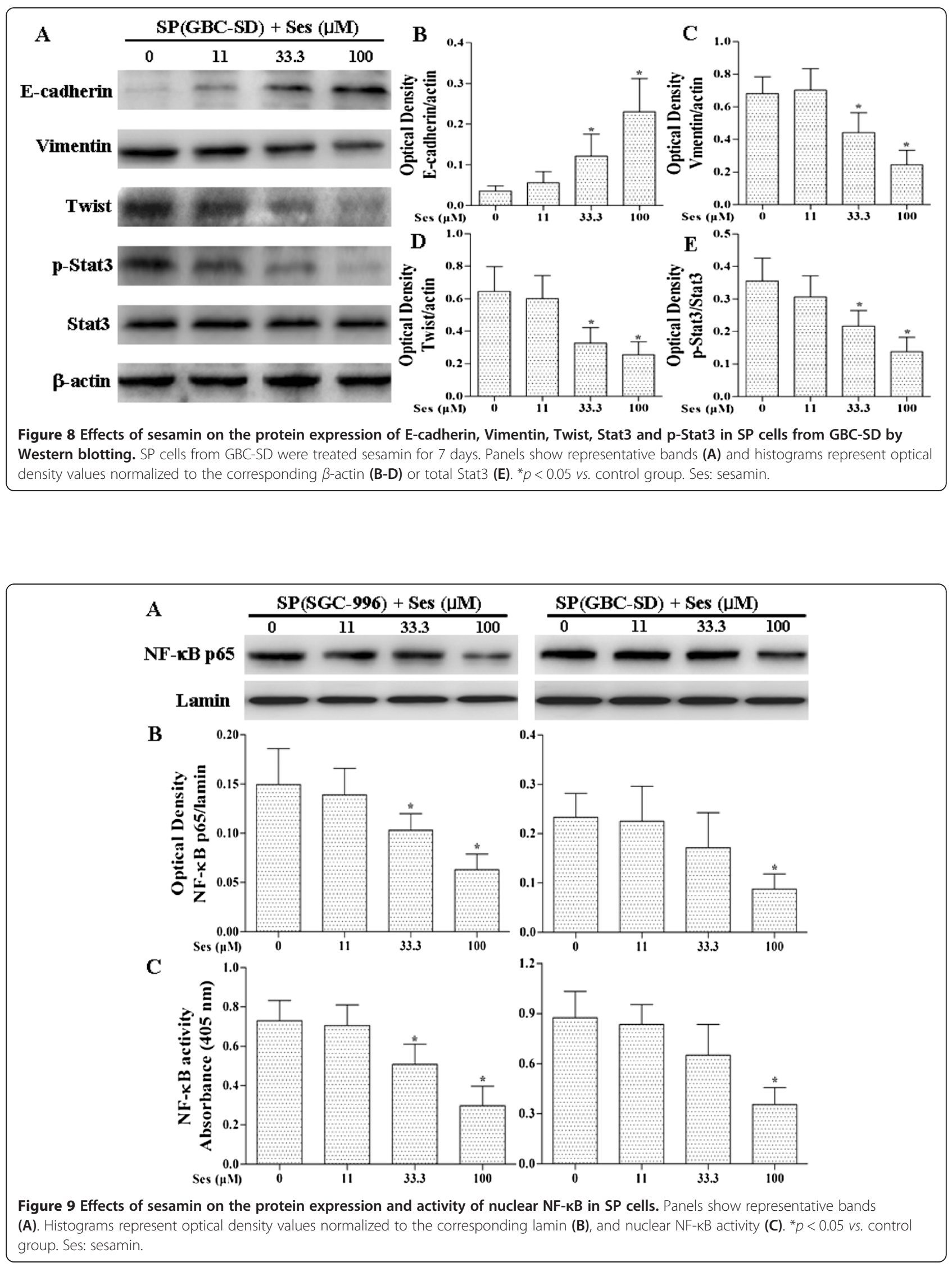


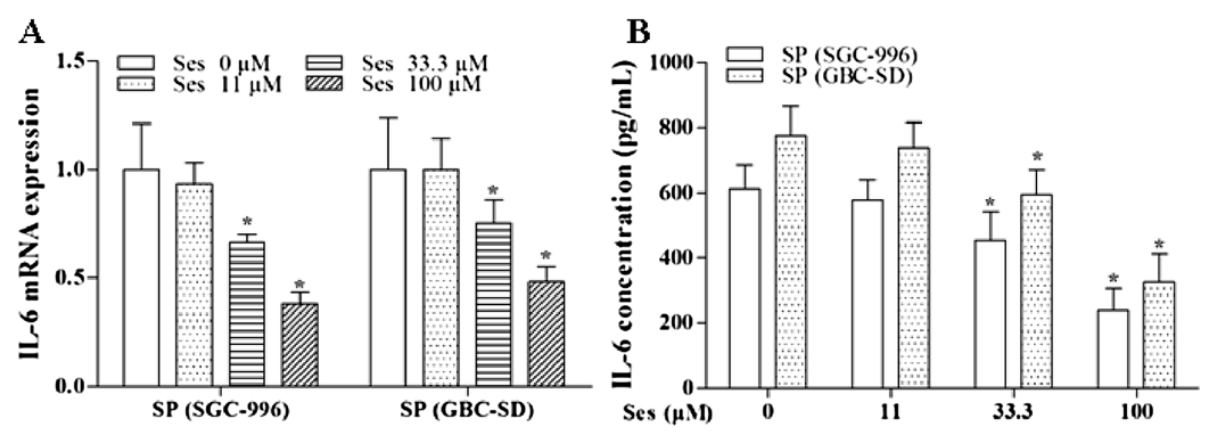

Figure 10 Effects of sesamin on the mRNA expression and protein level of IL-6 in SP cells. Histograms represent IL-6 mRNA expression (A) and protein level (B). ${ }^{*} p<0.05$ vs. control group. Ses: sesamin.

levels in SP cells while non-SP cells were with enhanced expression of the epithelial marker E-cadherin (Figure 3A). In other words, SP cells display a mesenchymal phenotype while non-SP cells an epithelial phenotype.

Plant-derived agents are now widely used in cancer therapy as supplemental or adjuvant agents. Food-derived agent, sesamin with its antitumor effects has drawn our attention [12-16]. In our study, we demonstrated that sesamin reduced the SP cells fraction and viability in a dose-dependent manner. Two explanations, either elimination $[27,28]$ or differentiation $[29,30]$ of SP cells may account for this phenomenon. The majority of the SP cells (more than 83\%) were viable at this situation (after treatment with sesamin), however, as determined by trypan blue exclusion (data not shown). In fact, Wanachewin et al. [31] reported that sesamin has the ability to trigger osteoblast differentiation by activation of the p38 and ERK MAPK signaling pathway. In this study, we obtained epithelial differentiation of SP cells without shifting the cells to standard differentiating

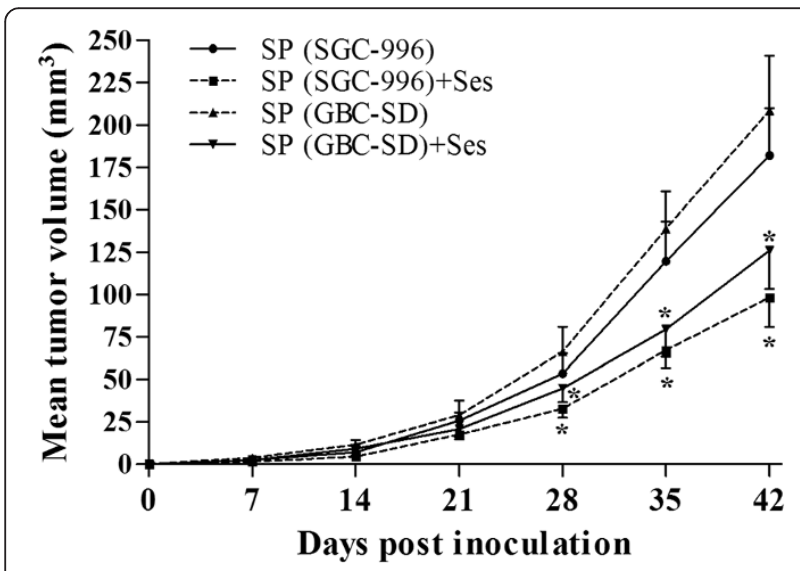

Figure 11 Effects of sesamin on SP cells-derived tumor growth in vivo. After pretreated with sesamin $(100 \mu \mathrm{M})$ for 7 days, $1 \times 10^{5}$ SP cells from both SGC-996 and GBC-SD were injected subcutaneously into 6 -week-old nude mice ( $n=6$ each group). Tumor volumes were measured weekly. ${ }^{*} p<0.05$ vs. control group. Ses: sesamin. conditions (add 10\% FBS in medium) but rather by maintaining the cells under non-differentiation conditions (which preserves in vitro their stem-like properties) in the presence of sesamin. Therefore, the decreased SP cells population may be attributed to the differentiation of SP cells.

The hypothesis could be demonstrated by the following results: First, after exposure to sesamin for 7 days, the single-cell suspensions derived from primary tumorspheres formed significantly fewer and smaller secondary tumor-spheres. Second, the differentiated cells achieved by shifting SP cells to differentiating conditions expressed the epithelial marker E-cadherin (Figure 4). Treatment with sesamin also resulted in the up-regulation of E-cadherin and down-regulation of Vimentin in SP cells, which was similar to the process of mesenchymal-epithelial transition. Third, sesamin modified the stem cell-like features. The sesamin-induced differentiation of SP cells was associated with a loss of properties that are considered the hallmarks of SP cells, such as the ability to form colonies, invade and to develop tumors in nude mice. Finally, we found that SP cells were more sensitive to a GBC therapy agent (cisplatin) after treatment with sesamin. This finding suggests that epithelial differentiation may sensitize SP cells to cytotoxic stimuli. In general terms, these results indicate that sesamin induces the differentiation of cancer stem-like SP cells from GBC.

EMT is mediated by the activation of transcription factors such as Twist, Snail and so on [32]. Ectopic expression of Twist results in down-regulation of E-cadherin (an epithelial marker), up-regulation of Vimentin (a mesenchymal marker) and expansion of the CSC population [33]. Cheng et al. [34] demonstrated that IL-6, Stat3 and Twist form a functional signaling axis to regulate pivotal oncogenic properties of cancer cells. Iliopoulos et al. [18] reported that the NF-kB-IL-6-Stat3 axis plays a vital role in the maintenance of CSCs. Taken together, it could be assumed that there exists a NF-kB-IL-6-Stat3-Twist axis in CSCs and it links the EMT programme and CSCs. In our study, the protein expression of Twist was much 
higher in cancer stem-like SP cells than in non-SP cells. We also demonstrated that the expression levels of nuclear NF-kB, IL-6 and p-Stat3 were enhanced in SP cells compared to non-SP cells.

In the meantime, interfering with this axis utilizing the NF-kB inhibitor [21,34], the IL-6 receptor antibody $[21,35]$, the Stat3 inhibitor $[21,30,36]$ or down-regulating the expression of Twist [26] reduces the CSC population and results in inhibition of tumor growth and metastasis. Generally, the NF-kB-IL-6-Stat3-Twist axis is vital for the maintenance of CSCs and association with the EMT process. Breaking this signal pathway may contribute to the epithelial differentiation of CSCs.

Aki et al. [13] and Lee et al. [37] reported that sesamin decreases the protein expression of NF- $\mathrm{kB}$ in breast cancer. Harikumar et al. [12] demonstrated that sesamin down-regulates constitutive and inducible NF- $\mathrm{BB}$ activation and expression in human chronic myeloid leukemia cell lines. In addition, Jeng et al. [17] showed that sesamin significantly inhibits IL-6 mRNA expression and protein level, and reduces nuclear NF- $\mathrm{kB}$ activity in microglial cells. In accordance with these reports, we found that sesamin also decreased IL-6 mRNA expression and protein level as well as nuclear NF- $\mathrm{kB}$ activity and protein expression in SP cells. Moreover, downregulated protein expression of p-Stat3 and Twist was also observed in SP cells in a dose-dependent manner after treatment with sesamin for 7 days. These results suggest that the epithelial differentiation effect of sesamin is associated with the broken of NF-kB-IL-6-Stat3Twist axis.

\section{Conclusions}

In summary, our study suggests that sesamin directs the epithelial differentiation of cancer stem-like SP cells from GBC. These effects are associated with the attenuation of NF-kB-IL-6-Stat3-Twist signal pathway. It meets the criteria for treatment strategies: Depletion of the CSC pool and generation of differentiated nontumorigenic cells with increased sensitivity to chemotherapy.

\section{Competing interests}

The authors declare that they have no competing interest.

\section{Authors' contributions}

Conceived and designed the experiments: XK, MZM, QS, ZWQ and JRY. Performed the experiments: XK, MZM, YZ, MZW, LQG, JXZ and GDW. Analyzed the data: XK, MZM, YZ and WG. Wrote the paper: XK, MZM, QS and JRY. All authors read and approved the final manuscript.

\section{Acknowledgements}

This research was supported by the Anhui Provincial Natural Science Foundation (grant number 1308085QH145) and the National Natural Science Foundation of China (Grant number 81272747).

\section{Author details}

'Department of Endocrinology, Xinhua Hospital, Shanghai Jiaotong University School of Medicine, Shanghai 200092, China. ${ }^{2}$ Department of
Pharmacology, Wannan Medical College, Wuhu, Anhui 241002, China. ${ }^{3}$ Department of General Surgery, Xinhua Hospital, Shanghai Jiaotong University School of Medicine, Shanghai 200092, China. ${ }^{4}$ Department of Gastroenterology, Yijishan Hospital Affiliated to Wannan Medical College, Wuhu, Anhui 241001, China. ${ }^{5}$ Department of Pharmacy, Wannan Medical College, Wuhu, Anhui 241002, China.

Received: 23 October 2013 Accepted: 15 July 2014

Published: 19 July 2014

\section{References}

1. Zhu AX, Hong TS, Hezel AF, Kooby DA: Current management of gallbladder carcinoma. Oncologist 2010, 15:168-181.

2. Gold DG, Miller RC, Haddock MG, Gunderson LL, Quevedo F, Donohue JH, Bhatia S, Nagorney DM: Adjuvant therapy for gallbladder carcinoma: the Mayo Clinic Experience. Int J Radiat Oncol Biol Phys 2009, 75:150-155.

3. Caldow PC, Groeschl RT, Quebbeman EJ, Gamblin TC: Recent advances in systemic therapies and radiotherapy for gallbladder cancer. Surg Oncol 2013, 22:61-67.

4. Yamashita T, Wang XW: Cancer stem cells in the development of liver cancer. J Clin Invest 2013, 123:1911-1918.

5. Abel EV, Simeone DM: Biology and clinical applications of pancreatic cancer stem cells. Gastroenterology 2013, 144:1241-1248.

6. Zhou J, Wulfkuhle J, Zhang H, Gu P, Yang Y, Deng J, Margolick JB, Liotta LA, Petricoin E 3rd, Zhang Y: Activation of the PTEN/mTOR/STAT3 pathway in breast cancer stem-like cells is required for viability and maintenance. Proc Natl Acad Sci U S A 2007, 104:16158-16163.

7. He K, Xu T, Xu Y, Ring A, Kahn M, Goldkorn A: Cancer cells acquire a drug resistant, highly tumorigenic, cancer stem-like phenotype through modulation of the PI3K/Akt/beta-catenin/CBP pathway. Int J Cancer 2013, doi:10.1002/ijc.28341. [Epub ahead of print].

8. He K, Xu T, Goldkorn A: Cancer cells cyclically lose and regain drugresistant highly tumorigenic features characteristic of a cancer stem-like phenotype. Mol Cancer Ther 2011, 10:938-948.

9. Yin L, Castagnino P, Assoian RK: ABCG2 expression and side population abundance regulated by a transforming growth factor beta-directed epithelial-mesenchymal transition. Cancer Res 2008, 68:800-807.

10. Hirose N, Inoue T, Nishihara K, Sugano M, Akimoto K, Shimizu S, Yamada H: Inhibition of cholesterol absorption and synthesis in rats by sesamin. J Lipid Res 1991, 32:629-638.

11. Kong $X$, Yang JR, Guo LQ, Xiong Y, Wu XQ, Huang $K$, Zhou Y: Sesamin improves endothelial dysfunction in renovascular hypertensive rats fed with a high-fat, high-sucrose diet. Eur J Pharmacol 2009, 620:84-89.

12. Harikumar KB, Sung B, Tharakan ST, Pandey MK, Joy B, Guha S, Krishnan S, Aggarwal BB: Sesamin manifests chemopreventive effects through the suppression of NF-kappa B-regulated cell survival, proliferation, invasion, and angiogenic gene products. Mol Cancer Res 2010, 8:751-761.

13. Akl MR, Ayoub NM, Sylvester PW: Mechanisms mediating the synergistic anticancer effects of combined gamma-tocotrienol and sesamin treatment. Planta Med 2012, 78:1731-1739.

14. Truan JS, Chen JM, Thompson LU: Comparative effects of sesame seed lignan and flaxseed lignan in reducing the growth of human breast tumors (MCF-7) at high levels of circulating estrogen in athymic mice. Nutr Cancer 2012, 64:65-71.

15. Wang HM, Cheng KC, Lin CJ, Hsu SW, Fang WC, Hsu TF, Chiu CC, Chang $\mathrm{HW}$, Hsu CH, Lee AY: Obtusilactone A and (-)-sesamin induce apoptosis in human lung cancer cells by inhibiting mitochondrial Lon protease and activating DNA damage checkpoints. Cancer Sci 2010, 101:2612-2620.

16. Tanabe H, Kuribayashi K, Tsuji N, Tanaka M, Kobayashi D, Watanabe N: Sesamin induces autophagy in colon cancer cells by reducing tyrosine phosphorylation of EphA1 and EphB2. Int J Oncol 2011, 39:33-40.

17. Jeng KC, Hou RC, Wang JC, Ping LI: Sesamin inhibits lipopolysaccharide-induced cytokine production by suppression of p38 mitogen-activated protein kinase and nuclear factor-kappaB. Immunol Lett 2005, 97:101-106.

18. Iliopoulos D, Hirsch HA, Struhl K: An epigenetic switch involving NF-kappaB, Lin28, Let-7 MicroRNA, and IL6 links inflammation to cell transformation. Cell 2009, 139:693-706.

19. Sullivan NJ, Sasser AK, Axel AE, Vesuna F, Raman V, Ramirez N, Oberyszyn TM, Hall BM: Interleukin-6 induces an epithelial-mesenchymal transition phenotype in human breast cancer cells. Oncogene 2009, 28:2940-2947. 
20. Xie G, Yao Q, Liu Y, Du S, Liu A, Guo Z, Sun A, Ruan J, Chen L, Ye C, Yuan Y: IL-6-induced epithelial-mesenchymal transition promotes the generation of breast cancer stem-like cells analogous to mammosphere cultures. Int J Oncol 2012, 40:1171-1179.

21. Gupta PB, Onder TT, Jiang G, Tao K, Kuperwasser C, Weinberg RA, Lander ES: Identification of selective inhibitors of cancer stem cells by high-throughput screening. Cell 2009, 138:645-659.

22. Morrison R, Schleicher SM, Sun Y, Niermann K, Kim S, Spratt DE, Chung CH, Lu B: Targeting the mechanisms of resistance to chemotherapy and radiotherapy with the cancer stem cell hypothesis. J Oncol 2011, 2011:941876.

23. Keysar SB, Jimeno A: More than markers: biological significance of cancer stem cell-defining molecules. Mol Cancer Ther 2010, 9:2450-2457.

24. Acloque H, Adams MS, Fishwick K, Bronner-Fraser M, Nieto MA: Epithelial-mesenchymal transitions: the importance of changing cell state in development and disease. J Clin Invest 2009, 119:1438-1449.

25. Kalluri R, Weinberg RA: The basics of epithelial-mesenchymal transition. J Clin Invest 2009, 119:1420-1428.

26. Mani SA, Guo W, Liao MJ, Eaton EN, Ayyanan A, Zhou AY, Brooks M, Reinhard F, Zhang CC, Shipitsin M, Campbell LL, Polyak K, Brisken C, Yang J, Weinberg RA: The epithelial-mesenchymal transition generates cells with properties of stem cells. Cell 2008, 133:704-715.

27. Li XX, Dong Y, Wang W, Wang HL, Chen YY, Shi GY, Yi J, Wang J: Emodin as an effective agent in targeting cancer stem-like side population cells of gallbladder carcinoma. Stem Cells Dev 2013, 22:554-566.

28. Lin C, Wang L, Wang H, Yang L, Guo H, Wang X: Tanshinone IIA inhibits breast cancer stem cells growth in vitro and in vivo through attenuation of IL-6/STAT3/NF-KB signaling pathways. J Cell Biochem 2013, 114:2061-2070.

29. Azzi S, Bruno S, Giron-Michel J, Clay D, Devocelle A, Croce M, Ferrini S, Chouaib S, Vazquez A, Charpentier B, Camussi G, Azzarone B, Eid P: Differentiation therapy: targeting human renal cancer stem cells with interleukin 15. J Natl Cancer Inst 2011, 103:1884-1898.

30. Sherry MM, Reeves A, WU JK, Cochran BH: STAT3 is required for proliferation and maintenance of multipotency in glioblastoma stem cells. Stem Cells 2009, 27:2383-2392.

31. Wanachewin O, Boonmaleerat K, Pothacharoen P, Reutrakul V, Kongtawelert P: Sesamin stimulates osteoblast differentiation through p38 and ERK1/2 MAPK signaling pathways. BMC Complement Altern Med 2012, 12:71.

32. Ouyang G, Wang Z, Fang X, Liu J, Yang CJ: Molecular signaling of the epithelial to mesenchymal tranisition in generating and maintaining cancer stem cells. Cell Mol Life Sci 2010, 67:2605-2618.

33. Fang X, Cai Y, Liu J, Wang Z, Wu Q, Zhang Z, Yang CJ, Yuan L, Ouyang G: Twist2 contributes to breast cancer progression by promoting an epithelial-mesenchymal transition and cancer stem-like cell self-renewal. Oncogene 2011, 30:4707-4720.

34. Cheng GZ, Zhang WZ, Sun M, Wang Q, Coppola D, Mansour M, Xu LM, Costanzo C, Cheng JQ, Wang LH: Twist transcriptionally induced by activation of STAT3 and mediates STAT3 oncogenic function. J Biol Chem 2008, 283:14665-14673.

35. Korkaya H, Kim Gl, Davis A, Malik F, Henry NL, Ithimakin S, Quraishi AA, Tawakkol N, D'Angelo R, Paulson AK, Chung S, Luther T, Paholak HJ, Liu S, Hassan KA, Zen Q, Clouthier SG, Wicha MS: Activation of an IL6 inflammatory loop mediates trastuzumab resistance in HER2+ breast cancer by expanding the cancer stem cell population. Mol Cell 2012, 47:570-584.

36. Lin L, Liu A, Peng Z, Lin HJ, Li PK, Li C, Lin J: STAT3 is necessary for proliferation and survival in colon cancer-initiating cells. Cancer Res 2011, 71:7226-7237

37. Lee CC, Liu KJ, Wu YC, Lin SJ, Chang CC, Huang TS: Sesamin inhibits macrophage-induced vascular endothelial growth factor and matrix metalloproteinase-9 expression and proangiogenic activity in breast cancer cells. Inflammation 2011, 34:209-221.

doi:10.1186/1472-6882-14-254

Cite this article as: Kong et al:: Differentiation therapy: sesamin as an effective agent in targeting cancer stem-like side population cells of human gallbladder carcinoma. BMC Complementary and Alternative Medicine 2014 14:254.

\section{Submit your next manuscript to BioMed Central and take full advantage of:}

- Convenient online submission

- Thorough peer review

- No space constraints or color figure charges

- Immediate publication on acceptance

- Inclusion in PubMed, CAS, Scopus and Google Scholar

- Research which is freely available for redistribution 